\title{
Aspectos recentes da absorção e biodisponibilidade do zinco e suas correlações com a fisiologia da isoforma testicular da Enzima Conversora de Angiotensina
}

\section{Recent aspects of zinc absorption and bioavailability and correlations with physiology of the testicular Angiotensin-Converting Enzyme}

Gilberto Simeone HENRIQUES ${ }^{1}$

Mário Hiroiuki HIRATA2

Sílvia Maria Franciscato COZZOLINO ${ }^{1}$

\section{RE S U M O}

A associação estável a macromoléculas e a flexibilidade da esfera de coordenação são propriedades intrínsecas do zinco e sua essencialidade encontra-se intimamente relacionada ao seu papel biológico, seja na ativação da função catalítica de enzimas, seja na estabilização das estruturas conformacionais de proteínas e ácidos nucléicos. 0 zinco é o segundo elemento traço essencial mais abundante no organismo humano e é necessário à atividade de mais de 300 enzimas dos 6 tipos de classes existentes. Estas características tornaram o metal e seus ligantes fontes de grande interesse para a nutrição experimental, já que o seu estudo converge para a determinação da biodisponibilidade do metal. Dentre esses ligantes, a isoforma testicular da Enzima Conversora de Angiotensina, sintetizada pelas células germinais masculinas, pode ser considerada um exemplo marcante de regulação molecular a partir da ligação do zinco, influenciando tanto a atividade quanto a concentração desta enzima e conseqüentemente a função testicular.

Termos de Indexação: zinco, enzima conversora de angiotensina, disponibilidade biológica, função testicular, enzimas.

\footnotetext{
1 Laboratório de N utrição-M inerais, Departamento de Alimentos e Nutrição Experimental, Faculdade de Ciências Farmacêuticas, Universidade de São Paulo. Av. Lineu Prestes, 580, Bloco 14, 05389-970, São Paulo, SP, Brasil. Correspondência para/Correspondenceto: G.S.HENRIQUES.E-mail: nativo@usp.br

2 Laboratório de Biologia Molecular Aplicada ao Diagnóstico, Departamento de Análises Clínicas e Toxicológicas, Faculdade de Ciências Farmacêuticas, Universidade de São Paulo.
} 


\section{A B S T R A C T}

The stable association with macromolecules and the flexibility of the coordination geometry are particular properties of zinc and its essentiality has been associated with the biological functions assigned to the metal, either by participating directly in chemical catalysis or by helping to mantain protein and nucleic acid structures and stability. Zinc is the second most abundant essential trace element in the human organism and it is necessary to the activity of more than 300 enzymes, covering all 6 classes of them. These properties make this metal and its ligands subjects of great interest for experimental nutrition, leading to the determination of zinc bioavailability. Among these ligands, the testicular Angiotensin- Converting Enzyme, synthesized by male germ cells, is an important example of the molecular regulation by zinc binding, determining both the activity and the concentrations of this enzyme, and affecting the testicular function.

Index terms: zinc, angiotensin-converting enzyme, biological availability, testicular function, enzymes.

\section{N T R O D U Ç Ã O}

A regulação da expressão gênica de proteínas de grande importância para os organismos vivos, por meio da concentração ou disponibilidade de determinados nutrientes, tem sido considerada uma das mais prováveis vias pelas quais é possível observar ou mesmo mensurar as manifestações gerais das deficiências e dos excessos desses elementos. Ingestões insuficientes, por meio da dieta, de micronutrientes como zinco, cobre, selênio, cálcio, carotenóides e de moléculas provenientes da hidrólise de macronutrientes como aminoácidos essenciais e ácidos graxos são capazes de produzir profundos efeitos pleiotrópicos no trato gastrintestinal e em outros órgãos e tecidos do organismo ${ }^{1}$. Essa capacidade de modulação de um único gene, tornando-o responsável, no fenótipo de um organismo, por múltiplos efeitos que não se relacionam, potencializa 0 efeito nutricional de alguns micronutrientes, os quais, estando presentes em pequenas quantidades na dieta e possuindo diferentes graus de biodisponibilidade de acordo com as transformações sofridas pela matriz alimentar durante os processos de digestão e absorção, proporcionam uma forte interação entre um fator ambiental característico das espécies vivas e fatores genéticos que influenciam ou determinam o metabolismo como um todo. Os tipos celulares do trato gastrintestinal, particularmente, sofrem rápidas modificações em sua proliferação e diferenciação, utilizando mecanismos que levam a alterações na expressão gênica, permitindo a sua adaptação a uma grande variedade de funções.

Particularmente o zinco, micronutriente a ser reportado neste trabalho, por sua ampla participação na estrutura de diversas proteínas do organismo, sobretudo catalisadores, exerce, dentre outros, os efeitos regulatórios anteriormente citados. 0 modelo clássico de interação direta do zinco com os processos de transcrição gênica está relacionado aos promotores dos genes que codificam para as metalotioneínas, em forma de múltiplos elementos responsivos a metais². Esses elementos são necessários para conferir a indução da transcrição do gene das metalotioneínas de maneira proporcional às concentrações de zinco presentes no organismo, disponível para exercer efeitos fisiológicos em certos tipos celulares em tecidos-alvo.

Adicionalmente aos mecanismos diretos de modulação da expressão gênica regulados pelo zinco, mecanismos indiretos, sensíveis ao estado nutricional relativo ao metal, parecem exercer influência decisiva na regulação gênica. Essas vias são aquelas nas quais mudanças metabólicas como a modulação da atividade enzimática ou de moléculas sinalizadoras dependem da ligação do zinco ${ }^{3}$. Tais mudanças podem então desencadear estímulos de retroalimentação, resultando 
em alterações moleculares nos processos de tradução e transcrição gênica ou mesmo modificações pós-transcricionais, em cadeias polipeptídicas que dependem da ligação de um ou mais átomos do metal em seu sítio de coordenação, seja ele de função estrutural, catalítica ou co-catalítica ${ }^{4}$. Esses mecanismos indiretos podem ainda desempenhar um papel na produção de efeitos associados com alterações do estado nutricional relativo ao zinco, incluindo-se aí aquelas resultantes da suplementação com o metal.

A intenção deste trabalho foi reunir evidências científicas que confirmam a biodisponibilidade do zinco como fator da dieta capaz de gerar e manter mecanismos indiretos que influenciam a expressão do gene da isoforma germinal da enzima conversora de angiotensina, a qual, diferentemente da isoforma somática, tem sua expressão restrita às células germinativas dos testículos e de suas estruturas anexas, proporcionando avanços na investigação de parâmetros relativos ao estado nutricional do zinco.

\section{Considerações a respeito dos aspectos bioinorgânicos do zinco}

A versatilidade das características físico-químicas do zinco constitui a base de sua extensa participação no metabolismo de proteínas, ácidos nucléicos, carboidratos, lipídios e, mais recentemente, tornou-se uma importante via de investigação na elucidação do processo de controle da expressão gênica e de outros mecanismos biológicos fundamentais. Dentre estas características, a associação estável do metal a macromoléculas, principalmente proteínas e ácidos nucléicos, e a flexibilidade de sua esfera de coordenação merecem destaque. Sob esta perspectiva, mais de 300 tipos diferentes de enzimas identificadas em diversas espécies vivas necessitam da coordenação de um ou mais átomos de zinco, podendo ser classificados como fatores catalítico, co-catalítico ou estrutural ${ }^{5}$ (Quadro 1 ).

A função catalítica pressupõe que o metal participa diretamente da catálise enzimática. Sua remoção ocasiona a inativação da enzima. Os sítios catalíticos têm como característica única a existência de uma esfera de coordenação aberta, ou seja, o poliedro que constitui o sítio de coordenação com o metal possui uma molécula de água ligada a outras três ou quatro moléculas de aminoácidos. Esta característica única permite diferenciar um típico sítio catalítico dos demais sítios co-catalíticos e estruturais, nos quais toda a esfera de coordenação é preenchida por cadeias laterais de aminoácidos, podendo ser facilmente detectados por métodos espectroscópicos como Ressonância Magnética Nuclear e Difração de Raios X. A molécula de água ligada ao zinco é um componente crítico do sítio catalítico, pois é a partir dela que o zinco pode ser ionizado a hidróxido de zinco (como acontece na anidrase carbônica), polarizado por uma base (como acontece na carboxipeptidase A), gerando um nucleófilo para a catálise, ou ainda ser deslocado pelo substrato ${ }^{6}$.

Quadro 1. Exemplos de algumas metaloenzimas nas quais o zinco atua como fator catalítico, co-catalítico, ou estrutural.

\begin{tabular}{ll}
\hline Tipo de átomo de zinco & \multicolumn{1}{c}{ Enzimas } \\
\hline Catalítico & $\begin{array}{l}\text { Álcool desidrogenase, Fosfatase alcalina, Carboxipeptidase A, Enzima Conversora de Angiotensina } \\
\text { (germinal), Anidrase carbônica II. }\end{array}$ \\
Co-catalítico & $\begin{array}{l}\text { Cobre-Zinco superóxido dismutase, fosfatase alcalina (com doisátomos de zinco e um de magnésio), } \\
\text { fosfolipase C, Nuclease P1, Leucina aminopeptidase. } \\
\text { Estrutural }\end{array}$ \\
\hline
\end{tabular}


Na função co-catalítica, o átomo de zinco pode aumentar ou diminuir a catálise, associando-se a outro átomo de zinco ou a um átomo de outro metal no sítio ativo da enzima e sua remoção não condiciona a perda da atividade ou estabilidade desta. Estes íons metálicos atuam de maneira concatenada, potencializando a catálise ${ }^{7}$. Um exemplo claro deste tipo de função pode ser visto na fosfolipase C. Esta enzima contém um primeiro átomo de zinco, denominado catalítico, geralmente ligado a uma molécula de água e a dois resíduos de histidina e um de glutamato, tornando-o semelhante a outros sítios catalíticos comumente encontrados. No entanto, o segundo átomo de zinco e o terceiro íon metálico (que pode ser um átomo de zinco ou de magnésio) estão unidos a ligantes menos comuns, como 0 oxigênio ou o nitrogênio provenientes de resíduos de aminoácidos. Há também uma ligação entre o segundo e o terceiro íon metálico, o que geralmente leva a uma geometria pentacoordenada.

Os átomos estruturais de zinco são necessários apenas à manutenção da estabilidade conformacional das proteínas, pois contribuem para a estabilização da estrutura quaternária de holoenzimas oligoméricas. 0 íon metálico é geralmente coordenado por quatro cadeias laterais de aminoácidos, dispostos em geometria tetraédrica, e a água é excluída da esfera interna de coordenação, diminuindo drasticamente a capacidade reacional do sistema. Cisteína é o aminoácido mais freqüentemente encontrado nesses sítios. Ao contrário dos sítios catalíticos de zinco, estes não apresentam um padrão regular de espaçamento entre as proteínas ligantes e apresentam uma maior flexibilidade nos parâmetros de acomodação do íon metálico (e.g. raio atômico, constantes de estabilidade), diminuindo a rigidez das estruturas secundáriase permitindo às proteínas com átomos estruturais de zinco desempenhar uma gama diversificada de funções ${ }^{8}$.

Diferentemente dos outros metais de transição do quarto período da classificação periódica dos elementos, o íon zinco $\left(\mathrm{Zn}^{2+}\right)$ possui um orbital $d$ cheio $\left(d^{10}\right)$, impossibilitando a sua participação em reações de óxido-redução (i.e. reações redox, nas quais necessariamente há uma dinâmica de troca de elétrons entre o par iônico), mas permitindo que ele seja o aceptor de um par de elétrons. Portanto, o zinco é o íon metálico ideal para funcionar como co-fator em reações que necessitam de um íon redox-estável, comportando-se como um ácido de Lew is durante a catálise ${ }^{9}$. Devido ao preenchimento dos orbitais d, a energia de estabilização do campo ligante dos íons $Z^{2+}{ }^{2}$ é igual a zero em todas as geometrias de ligação encontradas, fazendo uma das geometrias ser tão estável quanto as outras. Apesar de o metal assumir preferencialmente a geometria tetraédrica, com número de coordenação 4 , este pode variar de 2 a 8 , com suas respectivas geometrias, as quais vão desde a forma tetraédrica regular ou distorcida até a forma octaédrica. $A$ nulidade de efeitos do campo ligante contribui para que $0 \mathrm{Zn}^{2+}$ apresente tais configurações ${ }^{10}$. A ausência de uma barreira energética e a multiplicidade de geometrias de coordenação de acesso semelhante (i.e. indiferentemente de assumir uma ou outra geometria a energia necessária para manter a estabilidade da ligação é a mesma) permitem que as metaloenzimas dependentes de zinco alterem a reatividade do íon metálico e conseqüentemente aumentem a habilidade do zinco em catalisar transformações químicas, acompanhadas de mudanças em sua geometria de coordenação.

0 zinco é considerado um metal que se localiza na fronteira da disputa entre os ligantes pesados (não muito polarizáveis) e aqueles considerados leves (grandemente polarizáveis), não apresentando uma preferência pela coordenação com o oxigênio, com o nitrogênio ou com o enxofre.

M etaloenzimas e metaloproteínas, bem como as implicações a respeito de suas funções metabólicas, formam um conjunto de conhecimentos de significado importante para a tradução da estrutura química em funções 
biológicas múltiplas. Prova disso está na extensa bibliografia disponível a respeito das mais detalhadas características de metaloproteínas como as metalotioneínas ${ }^{11,12}$ e metaloenzimas tais como as carboxipeptidases ${ }^{6}$.

\section{Considerações a respeito da absorção do zinco}

O zinco é um espécie atômica pequena e se comporta quimicamente como um ácido de Lewis, o que determina a sua passagem pelas membranas biológicas tanto por mecanismos de difusão passiva quanto por transporte ativo. 0 metal é transferido do lúmen intestinal para o interior do enterócito, ultrapassando a borda em escova, e daí para a circulação sangüínea, em um processo envolvendo transporte paracelular e transporte mediado por carreadores ${ }^{13}$ (Figura 1).

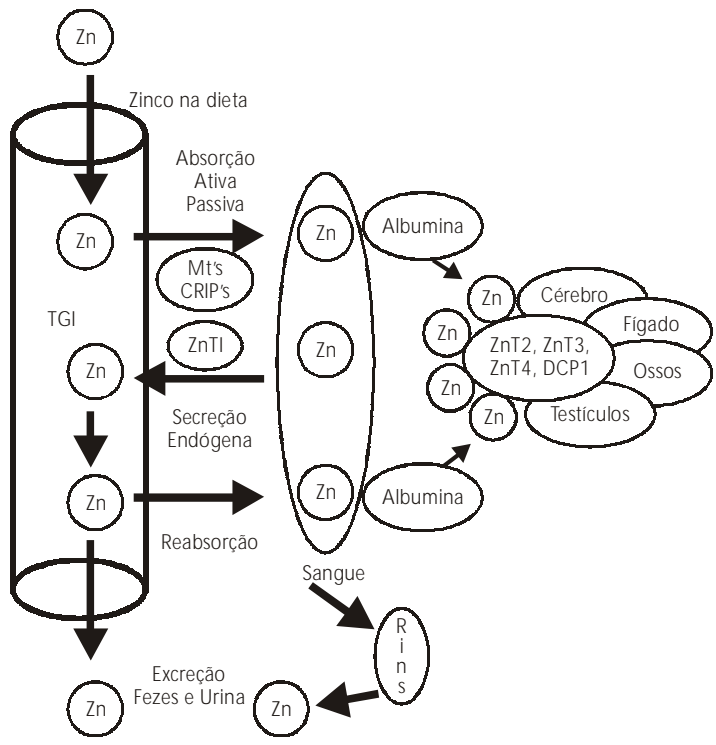

Figura 1. Esquema representativo dos mecanismos de digestão, absorção, aproveitamento por tecidos periféricos e excreção do zinco proveniente da dieta.

Dentro da célula da mucosa, o zinco é regulado por proteínas que ligam metais como as metalotioneínas e as proteínas intestinais ricas em cisteína (CRIP's). Hempe \& Cousins (1992) ${ }^{14}$ sugeriram um mecanismo no qual o zinco, após passar do meio extracelular para o citosol do enterócito, liga-se à CRIP, que funciona como uma proteína de transporte intracelular, passando por difusão em direção à membrana basolateral. A metalotioneína inibe a absorção de zinco, regulando a ligação do metal à CRIP, funcionando como uma espécie de marca-passo, ligando o metal transitoriamente e liberando-o gradativamente no citosol, podendo então associar-se à CRIP. Este modelo concilia a teoria na qual a absorção transcelular de zinco pode ser regulada por fatores da dieta e fatores fisiológicos que alteram a expressão gênica das metalotioneínas ou das CRIP's.

Segundo observaram Finley et al. (1995) ${ }^{15}$, estudando o transporte de zinco in vitro, em células de carcinoma de cólon humano da linhagem CACO-2, o zinco iônico livre é capaz de difundir-se através da célula, enquanto o zinco complexado não. Assim, quando grandes quantidades do íon livre estão presentes, a captação basolateral de zinco por um processo facilitado é muito pequena se comparada à captação por difusão. No entanto, se a afinidade do metal por um carreador for maior do que a sua afinidade pelos ligantes presentes no meio, ainda que a quantidade total de transporte mediado por carreadores seja pequena, este representará a maior parte do zinco absorvido pela célula a partir da membrana basolateral. 0 zinco que chega ao enterócito por intermédio do fluxo vascular dificilmente atinge o lúmem intestinal. Portanto, apesar da possibilidade de o zinco mover-se dentro da célula, da região basolateral para a região apical, muito pouco do metal move-se para fora da célula pela membrana apical da célula, reforçando a teoria da predominância da transferência no sentido apical-basolateral.

Os processos de transporte do metal são sensíveis à temperatura, ao tempo e ao $\mathrm{pH}$ nos quais se processam e parece haver a participação de componentes saturáveis e não saturáveis. A vanços recentes nas estratégias de biologia molecular permitiram a caracterização de uma família de transportadores de zinco em mamíferos. As proteínas caracterizadas até o momento são ZnT-1, ZnT-2, ZnT-3 e ZnT-4. A ZnT-1 é regulada 
diretamente pelas quantidades de zinco ingeridas e está associada ao efluxo do metal, localizando-se na membrana basolateral de enterócitos e de células tubulares renais. A ZnT-2 também está envolvida na exportação ou captação do zinco dentro de vesículas em diversos tipos celulares no intestino, nos rins e nos testículos. A ZnT-3 regula a captação de zinco em vesículas neuronais e possivelmente nos testículos e a ZnT-4, além de apresentar localização neuronal, também é responsável pela captação do zinco nas glândulas mamárias ${ }^{16}$. A descrição dessa família de transportadores parece ainda incompleta e não causará surpresa o aparecimento de novos componentes que possam auxiliar na elucidação dos intrincados caminhos percorridos pelo zinco desde a sua absorção até o seu aproveitamento em tecidos-alvo.

\section{Controle regulatório da absorção do zinco e sua influência sobre a concentração do metal em diferentes tecidos do organismo}

0 trato gastrintestinal é o local onde o zinco sofre maior controle homeostático. 0 mecanismo envolve ajustes tanto na absorção quanto na excreção endógena do metal, detectada nas fezes. É importante destacar, no entanto, que estes dois parâmetros não podem ser avaliados diretamente e todas as tentativas de determinação baseadas em modelos animais ou humanos, até 0 momento, carecem de validação ${ }^{17}$.

Os ajustes na abso rção gastrintestinal e na excreção endógena do metal são sinergísticos. As mudanças na excreção endógena parecem responder rapidamente a variações na ingestão tanto de concentrações um pouco acima quanto um pouco abaixo dos valores recomendados de zinco. A absorção de zinco responde mais lentamente, sendo o organismo capaz de lidar com flutuações maiores na concentração do metal ${ }^{18}$.

O zinco é o microelemento intracelular mais abundante e é encontrado em todos os tecidos corpóreos. Porém, $85 \%$ do seu total está concentrado nos músculos e ossos. Quando 0 suprimento fornecido por meio da dieta é muito baixo, ou se quantidades marginais do metal são consumidas por um período significativo, os mecanismos homeostáticos podem ser insuficientes para repor as perdas impostas, resultando em um balanço negativo de zinco. $\mathrm{Na}$ deficiência grave (concentrações inferiores a 0,6 $\mu \mathrm{mol}$ de zinco/g de ração), o conteúdo corpóreo total de zinco de animais experimentais pode diminuir a valores críticos de até $30 \%$ em relação a animais controle, mas esta perda não é uniforme entre os tecidos. As concentrações no plasma, fígado, ossos e testículos parecem ser as mais afetadas e têm, respectivamente, $45 \%, 19 \%$, $64 \%$ e $53 \%$ menos zinco que seus controles correspondentes ${ }^{19}$. 0 mecanismo envolvido em perdas tão significativas ainda não está totalmente esclarecido, porém, especula-se que o plasma é o grande sinalizador para alguns tecidos periféricos, os quais então iniciam uma espécie de liberação programada do metal. De acordo com estudos experimentais utilizando animais, os ossos são uma fonte significativa de zinco endógeno, quando o suprimento do metal pela dieta é baixo. Apesar disso, eles não são um estoque convencional de zinco no organismo. 0 declínio na concentração do metal durante períodos de depleção pode refletir uma redução na captação de zinco pelos ossos em resposta a uma diminuição da sua concentração no plasma e não propriamente uma liberação de zinco do tecido ósseo. 0 zinco é liberado dos ossos segundo uma cinética própria, na qual, em uma primeira etapa rápida, $10 \%$ a $20 \%$ do total do metal é reciclado. Em uma segunda etapa mais lenta, uma maior quantidade de zinco é liberada, mas sua utilização por tecidos periféricos é bem mais complexa, sugerindo um modelo de coordenação e parâmetros termodinâmicos próprios.

Quando ratos recém-desmamados foram submetidos a uma alimentação ad libitum, com rações contendo concentrações limítrofes de zinco, observou-se uma longa sobrevivência dos animais, 
com poucos sinais explícitos de deficiência. Eles sobreviveram às custas da utilização de seu próprio zinco corpóreo. Animais depletados desenvolvem tipicamente um modelo cíclico de ingestão alimentar que é de três a quatro dias mais extenso quando comparado ao de animais controle, ocasionando o catabolismo em tecidos com quantidades significativas de zinco, liberando este elemento para atuar em funções metabólicas críticas. 0 zinco proveniente do catabolismo de certos tecidos é aproveitado com grande eficiência por outros tecidos onde sua utilização metabólica é prioritária ${ }^{20}$.

Ajustes na absorção gastrintestinal de zinco e na excreção intestinal do metal são as maneiras primárias pelas quais o organismo mantém as concentrações teciduais de zinco, mesmo sob variações nos níveis de ingestão. A avidez em reter o metal apresentada por alguns tecidos durante períodos de deficiência contribui para a sensível diminuição de sua perda endógena e para o aumento geral da eficiência do aproveitamento do metal proveniente da dieta. A manutenção de ingestões limítrofes de zinco desencadeia mecanismos secundários de controle da sua concentração que incluem a redução de sua excreção urinária, aumentos na recirculação plasmática e aumento da retenção do zinco endógeno por alguns tecidos do organismo ${ }^{21}$.

\section{Estudos de biodisponibilidade de zinco}

O conhecimento das moléculas que contêm zinco e a elucidação de sua bioquímica ampliaram as fronteiras da química bioinorgânica, despertando o interesse de áreas como a nutrição, fisiologia e medicina. Para a nutrição, mais especificamente, grande interesse tem sido dispensado aos estudos objetivando acessar ou determinar a biodisponibilidade do zinco nos sistemas biológicos ${ }^{22,23}$. Neste sentido, as mais diversas metodologias têm sido desenvolvidas e aplicadas, desde estudos clássicos utilizando a depleção e repleção do metal ${ }^{24,25}$, até pesquisas usando radioisótopos, isótopos estáveis e os modelos experimentais desenvolvidos a partir de culturas de células, que mimetizam o processo de absorção e transporte do zinco para o meio intracelular ${ }^{26}$.

Nos últimos anos, porém, tem-se observado a tendência em investigar sítios cada vez mais específicos, cuja fisiologia depende direta ou indiretamente da ligação ou do comportamento bioinorgânico de átomos do metal. Os modelos experimentais de tais estudos, em geral, incluem a análise de parâmetros bioquímicos sensíveis à depleção e à repleção do zinco veiculado por meio de regimes alimentares formulados para cada propósito determinado. Estes parâmetros bioquímicos são definidos segundo a órgão-especificidade envolvida na investigação e vão desde a medida de zinco no soro e no plasma, em células do sangue como eritrócitos e linfócitos e em órgãos como fígado, rins e testículos ${ }^{27,28}$, até as mais recentes quantificações e determi-nações do comportamento cinético de metaloproteínas e metaloenzimas, as quais têm sua função catalítica e estabilidade conformacional dependentes da ligação de átomos do metal aos seus sítios de coordenação ${ }^{12}$.

Considerando-se a incessante busca do estabelecimento de parâmetros sensíveis e precisos de avaliação do estado nutricional relativo ao zinco, o estudo sistematizado das isoformas da Enzima Conversora de Angiotensina (ECA) tem possibilitado a abertura de caminhos de investigação outrora limitados pela baixa resolução das técnicas analíticas e pela própria amplitude do conceito de biodisponibilidade. Aqui deve-se entender a ECA somática como um exemplo de proteína amplamente distribuída e encontrada em diversos compartimentos do organismo e a isoforma testicular (germinal) da ECA como um exemplo de grande especificidade fisiológica, determinada não somente pela cadeia polipeptídica, mas também pelo tipo de coordenação estabelecida com os átomos de zinco. 


\section{Características gerais da Enzima Conversora de Angiotensina}

A Enzima Conversora de Angiotensina (ECA), descoberta em 1954, por meio de sua detecção no plasma de eqüinos ${ }^{29}$, é uma metaloprotease (dipeptidil carboxipeptidase) dependente de zinco, que catalisa a hidrólise de dipeptídeos carboxi-terminais a partir de oligopeptídeos como a angiotensina I (AI) ${ }^{30}$ e a bradicinina (BK). Possui duas isoformas, uma delas somática, de distribuição sistêmica, encontrada em grandes concentrações na superfície luminal das células endoteliais vasculares, que é composta de uma cadeia polipeptídica simples e longa, coordenando dois átomos de zinco, em dois domínios distintos, dos quais apenas um sítio relaciona-se à função catalítica. A isoforma somática da ECA é um importante componente do sistema renina-angiotensina-aldosterona. Sua ação clássica neste sistema compreende a conversão do peptídeo inativo angiotensina I (AI) no potente vasoconstritor angiotensina II (AII), que por sua vez estimula a liberação do hormônio esteróide aldosterona do córtex da glândula adrenal, ocasionando a retenção de sódio e desempenhando papel fundamental na manutenção da pressão sanguínea e na homeostase hidroeletrolítica.

A outra isoforma, de peso molecular menor, coordenando um átomo de zinco por mol de enzima ${ }^{31}$, tem sido relatada como específica dos testículos das mais variadas espécies animais. Esta isoforma testicular não é expressa nos órgãos que compõem o sistema reprodutor masculino até os animais atingirem a puberdade, período no qual ocorre grande aumento em sua atividade, estabilizando-se na idade madura, o que sugere a existência de um mecanismo hormonal de controle da sua síntese. Segundo relataram Velletri et al. (1985) ${ }^{32}$, investigando esta hipótese, ratos pré-púberes submetidos a hipofisectomia perdiam a capacidade de sintetizar a isoforma testicular da ECA quando púberes. Neste caso, reposições hormonais com testosterona, hormônios folículo-estimulante (FSH) e luteinizante (LH), se feitas logo após a hipofisectomia, foram capazes de manter a atividade da enzima Conversora de Angiotensina, indicando a necessidade da manutenção da glândula pituitária íntegra e conseqüentemente a estimulação da esteroideogênese nos testículos, para o processo de síntese da enzima.

\section{Características moleculares da isoforma testicular da ECA}

A isoforma testicular da enzima Conversora de Angiotensina, isolada e seqüenciada a partir da obtenção do DNA complementar (cDNA), é um polipeptídeo constituído de 732 resíduos de aminoácidos, incluindo-se um peptídeo sinalizador amino-terminal de 21 resíduos de aminoácidos. Os primeiros 67 aminoácidos da ECA testicular são exclusivos dessa isoforma, caracterizando uma extremidade amino-terminal diferente entre as duas isoformas, enquanto o restante da proteína é idêntica à metade carboxi-terminal da enzima sistêmica ${ }^{33}$. A análise do DNA para a ECA no genoma haplóide de camundongos revelou a existência de um gene simples codificando para as diferentes isoenzimas. A análise da correspondência do sítio catalítico sugere que a enzima sistêmica seja resultante da duplicação do gene, enquanto a isoforma testicular corresponde à forma ancestral, não duplicada.

Segundo Howard et al. (1990) ${ }^{34}$, o mRNA testicular começa a ser transcrito na junção da estrutura exon-intron do molde de DNA da isoforma sistêmica, em uma seqüência intrônica (dentro do $12^{\circ}$ intron). Sendo assim, a enzima testicular não é resultante de um splicing alternativo do RNA, mas de um início de transcrição em um sítio exclusivo dentro do gene que codifica para a ECA. A unidade de RNA testicular não contém uma seqüência TATA box autêntica (seqüência de timina, adenina, timina, adenina, a qual em geral determina o início de transcrição), mas apenas uma seqüência similar TATT (timina, adenina, timina, timina) 27 bases antes (upstream) do sítio de iniciação 
transcricional, junto a seqüências repetidas e invertidas (palindrômicas), na região regulatória específica do gene. A falta do conhecimento de um sítio regulatório comum na região $5^{\prime}$ dessa unidade de transcrição pode oferecer uma explicação plausível para a exclusividade da expressão dessa isoforma nos testículos. Demonstrou-se que a transcrição da ECA testicular é controlada por um promotor intragênico específico das células germinativas do aparelho reprodutor masculino, contido em um fragmento de 682 pares de base, localizado imediatamente antes (upstream) do sítio de iniciação de transcrição para essa isoforma.

Em estudos mais recentes, Kessler et al. $(1998)^{35}$, utilizando um gene repórter desenvolvido em camundongos transgênicos, o qual expressa o gene da $\beta$-galactosidase, identificaram um elemento pontual responsivo ao CAMP, contido no DNA genômico e essencial para a ativação transcricional do mRNA para a enzima testicular. Esse elemento foi então denominado elemento responsivo ao CAMP (CRE like) e sua função foi definida como sendo um regulador da expressão do mRNA para a ECA testicular, localizado na extremidade 5' do sítio de iniciação transcricional. Delmas \& Sassone-Corsi (1994) $)^{36}$ primeiramente descreveram uma família de fatores de transcrição que inclui um membro específico dos testículos (CREM ${ }_{\text {t }}$, com participação na regulação transcricional positiva de vários genes testículo-específicos como o das protaminas e da calspermina ${ }^{37}$.

\section{Zinco, Enzima Conversora de Angiotensina e função testicular}

A função da ECA nos testículos é ainda desconhecida, mas sua atividade sofre influência do estado nutricional relativo ao zinco em animais de laboratório. Segundo Reeves \& Rossow $(1993)^{38}$, se a deficiência de zinco for induzida em ratos pré-púberes, a expressão da ECA é grandemente reduzida e sua atividade não é restaurada após um período de sete dias de repleção com o mineral, apontando para uma correlação negativa entre a idade do animal e os efeitos da deficiência do zinco sobre a expressão e a atividade da enzima conversora de angiotensina em sua isoforma testicular. Estudando a transcrição do RNA mensageiro (mRNA), Stallard \& Reeves (1997) ${ }^{39}$ concluíram que a deficiência de zinco em ratos adultos pode levar à redução do mRNA que codifica para a ECA testicular. Conseqüentemente, a queda da atividade da enzima está diretamente associada à diminuição de sua concentração.

Henriques \& Cozzolino $(2001)^{40}$, em recente estudo sobre o efeito da suplementação com zinco sobre a indução de metalotioneínas, encontraram valores expressivos desta metaloproteína nos testículos de ratos jovens, acompanhados da manutenção das concentrações teciduais de zinco. Em grupos de animais que receberam rações nas quais a biodisponibilidade do metal era menor, esta manutenção se fez às custas da diminuição da concentração de zinco nos fêmures dos animais, sugerindo uma redistribuição do pool de zinco para tecidos onde há maior síntese e expressão de metaloproteínas e metaloenzimas. As metalotioneínas, particularmente por suas baixas constantes de dissociação, são as grandes responsáveis pelo fornecimento de átomos de zinco para proteínas como as CRIP's nos enterócitos e para fatores de trancrição como TFIIIA (fator de transcrição IIIA). Especula-se que algo semelhante possa ocorrer entre metalotioneínas e a enzima Conversora de Angiotensina nos testículos.

As evidências experimentais de que a deficiência de zinco prejudica o desenvolvimento do sistema reprodutor, bem como o seu funcionamento, estão amplamente relatadas na literatura científica, como nos estudos discutidos no artigo escrito por Mason et al. (1982) ${ }^{24}$, no qual os autores estabelecem correlações entre dados bioquímicos e resultados de exames histológicos detalhados de diferentes regiões do sistema reprodutor masculino de ratos pré e pós-púberes submetidos a regimes alimentares contendo diferentes concentrações de zinco. 
Conforme conclusão dos autores, a deficiência transitória deste mineral em animais que atingiram ou estão por atingir a puberdade é passível de reversão por meio da repleção com o mineral, fato que não foi observado quando a deficiência foi induzida após o perío do da puberdade.

0 zinco desempenha um papel essencial no sistema reprodutor de machos e fêmeas das mais variadas espécies animais. Ele é necessário para a ocorrência da síntese e da secreção dos hormônios luteinizante (LH) e folículo-estimulante (FSH), para a diferenciação das gônadas, para o crescimento testicular, para a formação e maturação dos espermatozóides, para a esteroideogênese e para a manutenção de parâmetros normais de fertilidade. Os efeitos endócrinos de andrógenos e estrógenos são mediados por proteínas do tipo dedos de zinco, localizadas em regiões conservadas de genes dos receptores nucleares. Como o metal está envolvido na secreção de LH, FSH e prolactina, sua deficiência deprime a esteroideogênese, bloqueando a função do LH e as enzimas estereo idogênicas. Ratos submetidos a alimentação com rações marginalmente deficientes em zinco apresentam células de Leydig menores que o normal e com retículo endoplasmático alterado. Om \& Chung $(1996)^{41}$ evidenciaram em ratos machos deficientes em zinco concentrações de $\mathrm{LH}$ e testosterona reduzidos e metabolismo hepático de esteróides e concentrações de hormônios esteróides sexuais alterados, concluindo que a deficiência do metal contribui significativamente para a patogênese das disfunções reprodutivas masculinas como infertilidade, hipogonadismo e feminilização.

A presença do zinco nos testículos é crítica para a espermatogênese. Sua deficiência induz a atrofia dos túbulos seminíferos e falhas neste processo em ratos, associando-se o exame de cortes histológicos e a contagem de células espermáticas viáveis à redução da atividade da ECA em ratos deficientes em zinco, e concluindo-se que esta redução é grandemente causada pelo subdesenvolvimento das células germinativas, os quais por sua vez são diretamente influenciadas pela diminuição da concentração de testosterona apresentada por esses animais. A administração de inibidores marcados da ECA, como $\left[{ }^{3} \mathrm{H}\right]$ captopril, comprova que esses inibidores são ligados primariamente e com grande avidez pela fração de células germinativas ${ }^{32}$. Essa inibição afeta marcadamente a reação do acrossomo com o óvulo, diminuindo a capacidade do espermatozóide de fecundá-lo, e os problemas de fertilidade não parecem estar ligados às baixas concentrações de angiotensina II, pois camundongos geneticamente modificados, deficientes em angiotensinogênio, não apresentam infertilidade ${ }^{42}$.

Hagaman et al. (1998) ${ }^{43}$ observaram que camundongos Knockout (os quais não expressavam nenhuma das isoformas da ECA) apresentavam graves comprometimentos estruturais e fisiológicos nas células germinativas. Ramaraj et al. (1998) ${ }^{44}$ associaram os danos ao sistema reprodutor à ausência da ECA testicular no esperma de ratos transgênicos.

\section{Modelo de correlação entre a deficiência de zinco e sua potencial influência sobre a Enzima Conversora de Angiotensina e moléculas sinalizadoras}

Segundo o modelo proposto (Figura 2), a deficiência de zinco na dieta (cujos efeitos gerais são indicados pelas setas em negrito) provoca a diminuição das concentrações intracelulares ou extracelulares de zinco ou mesmo ambas, diminuindo a disponibilidade do metal para enzimas dependentes de zinco como metalopeptidases extracelulares ativadoras de hormônios na membrana celular, podendo resultar em uma diminuição da ligação aos sítios catalíticos e conseqüentemente em perda da atividade enzimática. Este decréscimo na atividade enzimática, por sua vez, pode reduzir a quantidade de hormônio ativo, resultando na 
desrepressão do mecanismo de inibição autócrina da produção do mRNA de pré-pró-hormônios. Isto então fará com que haja um aumento das quantidades de mRNA para determinados hormônios, e, além disso, a saída do zinco de holoenzimas aumentará a concentração de apoenzimas, os quais serão um alvo fácil para os mecanismos de degradação protéica.

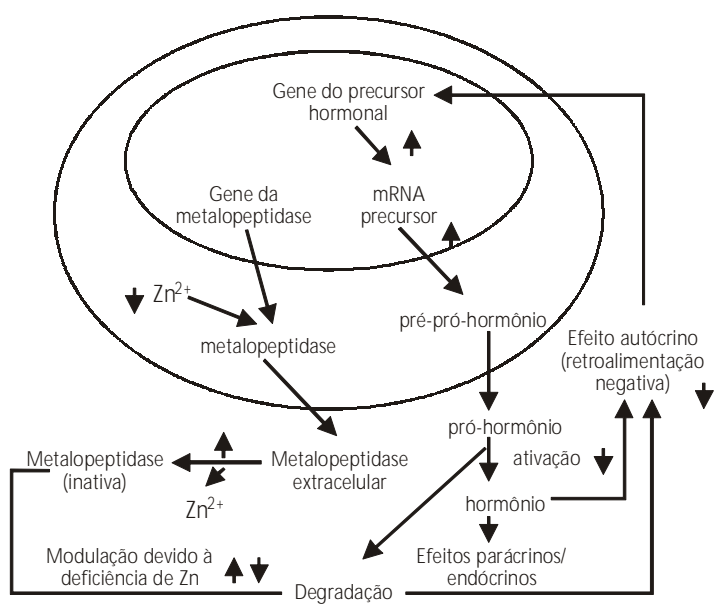

Figura 2. Modelo hipotético da possível influência da deficiência de zinco sobre a atividade e a concentração da Enzima Conversora de Angiotensina e moléculas sinalizadoras (Adaptado a partir de Blanchard \& Cousins, 2000) . $^{3}$

A partir deste modelo, é possível se especular a respeito da potencialização dos efeitos do zinco sobre a regulação da isoforma testicular da enzima conversora de angiotensina, a qual teria os seus efeitos amplificados para outros tecidos envolvidos na função reprodutora, passando a fazer parte dos complexos mecanismos que controlam a homeostase do sistema reprodutor de várias espécies animais.

\section{O N C L U S Ã O}

Em conjunto, os estudos envolvendo depleção e repleção de zinco e seus reflexos sobre a atividade da Enzima Conversora de Angiotensina, sobretudo da isoforma encontrada nos testículos, não apresentam caráter totalmente conclusivo quando a abordagem refere-se à biodisponibilidade do zinco. A maioria das investigações ou se preocupa com as conseqüências da deficiência limítrofe do metal e da possibilidade da reversão dos efeitos negativos por ela causados, ou com os aspectos bioinorgânicos, buscando a caracterização do papel da ECA nos testículos.

A sensibilidade desta isoforma da ECA às variações de ingestão de zinco alimentar torna estratégica a busca da caracterização de parâmetros bioquímicos capazes de representar significativamente 0 estado nutricional referente a este metal essencial. Sua escolha para avaliação da biodisponibilidade reúne características importantes que a diferenciam das demais metaloenzimas dependentes de zinco e de sua isoforma somática. Dentre estas encontram-se a maneira singular de coordenar apenas um áto mo de zinco, sua localização em um tecido com funções bem definidas, que sofre controle regulatório endócrino por meio de mecanismos extensamente estudados e elucidados, e seu intercâmbio com outras metaloproteínas, mobilizando o zinco em situações nas quais a deficiência do metal implique em prejuízos a funções primordiais como a espermatogênese. Assim, maiores investigações deverão ser direcionadas à observação dos efeitos da administração de zinco alimentar, objetivando um entendimento mais amplo dos três efeitos - deficiência, reposição e suplementação, bem como de suas correlações com os processos de aproveitamento e utilização do mineral pelos organismos vivos, conseqüentemente aumentando o conhecimento a respeito de sua biodisponibilidade.

\section{REFERÊ N CIAS}

1. Blanchard RK, Cousins RJ. Differential display of intestinal mRNA's regulated by dietary zinc. Proc Natl Acad Sci USA 1996; 93:6863-8.

2. Chen $X$, Agarwal A, Giedroc DP. Structural and functional heterogeneity among the zinc fingers of human MRE-binding transcription factor- 1 . Biochemistry 1998; 37(32):11152-61. 
3. Blanchard RK, Cousins RJ. Regulation of intestinal gene expression by dietary zinc: Induction of uroguanylin mRNA by zinc deficiency. J Nutr 2000; 130:1393S-8S.

4. Coleman JE. Zinc proteins: enzymes, storage proteins, transcription factors and replication proteins. Ann Rev Biochem 1992; 61:897-946.

5. Valee BL, Falchuk KH. The biochemical basis of zinc physiology. Physiol Rev 1993; 73:79-111.

6. Valee BL, Auld DS. Zinc coordination, function and structure of zinc enzymes and other proteins. Biochemistry 1990; 29:5647-59.

7. Valee BL, Auld DS. New perspectives on zinc biochemistry: cocatalytic sites in multi-zinc enzymes. Biochemistry 1993; 32:6493-500.

8. Ippolito JA, Baird TT, M CGee SA, Christianson DW, Fierke $C A$. Structure-assisted redesign of a protein-zinc binding site with femtomolar affinity. Proc Natl Acad Sci 1995; 92:5017-21.

9. Butler A. Acquisition and utilization of transition metal ions by marine organisms. Sci Am 1998; 281:207-9.

10. Kaim W, Schwederski B. Zinc: structural gene-regulatory functions and the enzymatic catalysis of hydrolysis or condensation reactions. In: Kaim W, Schwederski B, editors. Bioinorganic chemistry: inorganic elements in the chemistry of life, an introduction and guide. West Sussex: Wiley; 1996. p.242-64.

11. Margoshes M, Valee BL. A cadmium-and-zinc containing protein from equine kidney cortex. J Am Chem Soc 1957; 79(17):4813-4.

12. Kägi JHR. Metallothionein III. Experientia 1993; 53(suppl):29-55.

13. Salgueiro M J, Zubillaga M, Lysionek A, Sarabia M I, Caro R, De Paoli T, et al. Zinc as an essential micronutrient: a review. Nutr Res 2000; 20(5):737-55.

14. Hempe JM, Cousins RJ. Cysteine-rich intestinal protein and intestinal metallothionein: an inverse relationship as a conceptual model for zinc absorption in rats. J Nutr 1992; 122(1):89-95.
15. Finley JW, Briske-Anderson M, Reeves PG, Johnson LK. Zinc uptake and transcellular movement by CACO-2 cells: studies with media containing fetal bovine serum. J Nutr Biochem 1995; 6:137-44.

16. Cousins RJ, MCmahon RJ. Integrative aspects of zinc transporters. J Nutr 2000; 30:1384S-7S.

17. Cozzolino SMF. Biodisponibilidade mineral. Rev Nutr 1997; 10(2):87-98.

18. Krebs NF. Overview of zinc absorption and excretion in the human gastrointestinal tract. J Nutr 2000; 130:1374S-7S.

19. King JC, Shames DM, Woodhouse LR. Zinc homeostasis in humans. J Nutr 2000; 130:1360S-6S.

20. Beshgetoor D, Lönerdal B. Effect of marginal maternal zinc deficiency in rats on mammary gland zinc metabolism. J Nutr Biochem 1997; 8:573-8.

21. Cousins RJ. Zinc. In: Ziegler EE, Filer LJ, editors. Present Knowledge in nutrition. Washington: ILSI Press; 1996. p.293-306.

22. O'Dell BL. Effect of dietary components upon zinc availability. Am J Clin Nutr 1969; 22(10):1315-22.

23. Hoadley JE, Leinart AS, Cousins AS. Kinetic analisys of zinc uptake and serosal transfer by vascularly perfused rat intestine. Am J Physiol 1987; 252:G825-31.

24. Mason KE, Burns WA, Smith JC. Testicular damage associated with zinc deficiency in pre-and postpubertal rats: Response to zinc repletion. J Nutr 1982; 112:1019-28.

25. Reeves PG, O'Dell BL. Effects of dietary zinc deprivation on the activity of angiotensin-converting enzyme in serum of rats and guinea pigs. J Nutr 1986; 116:128-34.

26. Jackson MJ. The assessments of bioavailability of micronutrients: Introduction. Eur J Clin Nutr 1997; 51(suppl):S1-S2.

27. Mawson CA, Fischer MI. Zinc in genital organs of rat. Nature 1951; 167(4156):859.

28. Reeves PG. Copper status of adult male rats is not affected by feeding an AIN 93G-based diet containing high concentrations of zinc. J Nutr Biochem 1996; 7:166-72. 
29. Skeggs LT, M arsh WH, Kahn JR., Shumway NP. The existence of two forms of hypertensin. J Exp M ed 1954; 99:275-82.

30. Skeggs LT, Kahn JR, Shumway NP. The preparation and function of the hypertensin-converting enzyme. J Exp Med 1956; 103:295.

31. Ehlers M RW, Riordan JF. Angiotensin-converting enzyme: Zinc-and inhibitor-binding stoichiometries of the somatic and testis isozymes. Biochemistry 1991; 30:7118-26.

32. Velletri PA, Aquilano DR, Brucknick E, Tsai-M orris $\mathrm{CH}$, Dufau ML, Lovemberg W. Endocrinological control and cellular localization of rat testicular angiotensin-converting enzyme (EC 3.4.15.1). Endocrinology 1985; 116(6):2516-22.

33. Ehlers M R, FoxEA, Strydom DJ, Riordan JF. Molecular cloning of human testicular angiotensin-converting enzyme: the testis isozyme is identical to the C-terminal half of endothelial angiotensin-converting enzyme. Proc Natl Acad Sci USA 1989; 86(20):7741-5.

34. Howard TE, Shai S, Langford KG, Martin BM, Bernstein KE. Transcription of testicular angiotensin-converting enzyme (ACE) is initiated within the $12^{\text {th }}$ intron of the somatic ACE gene. Mol Cell Biol 1990; 10(8):4294-303.

35. Kessler SP, Rowe TM, Blendy JA, Erickson RP, Sem GC. A cyclic AMP response element in the angiotensin-converting enzyme gene and the transcription factor CREM are required for transcription of the mRNA for the testicular isozyme. J Biol Chem 1998; 273:9971-5.

36. Delmas V, Sassone-Corsi P. The key role of CREM in the CAMP signaling pathway in the testis. Mol Cell Endocrinol 1994; 100:121-4.
37. Ha H., van Wijnen AJ, Hecht NB. Tissue-specific protein-DNA interactions of the mouse protamine 2 gene promoter. J Cell Biochem 1997; 64: 95-105.

38. Reeves PG, Rossow KL. Zinc deficiency affects the activity and protein concentration of angiotensinconverting enzyme in rat testes. Proc Soc Exp Biol Med 1993; 203:336-42.

39. Stallard L, Reeves PG. Zinc deficiency in adult rats reduces the relative abundance of testis-specific Angiotensin-converting enzyme mRNA. J Nutr 1997; 127:25-9.

40. Henriques GS, Cozzolino SM F. Determination of metallothionein levels in tissues of young rats fed zinc-enriched diets. Rev Nutr 2001; 14(3):163-9.

41. Om AS, Chung KW. Dietary zinc deficiency alters 5 $\alpha$-reduction and aromatization of testosterone and androgen and estrogen receptors in rat liver. J Nutr 1996; 126:842-8.

42. Foresta C, M ioni R, Rossato M, Varotto A, Zorzi M. Evidence for the involvement of sperm angiotensin converting enzyme in fertilization. Int J Androl 1991; 14:333-9.

43. Hagaman JR, Moyer JS, Bachman ES, Sibony M, M agyar PL, Welch JE, et al. Angiotensin-converting enzyme and male fertility. Proc Natl Acad Sci USA 1998; 95(5):2552-7.

44. Ramaraj P, Kessler SP, Colmenares C, Sem GC. Selective restoration of male fertility in mice lacking angiotensin-converting enzymes by sperm-specific expression of the testicular enzyme. J Clin Invest 1998; 102:371-78.

Recebido para publicação em 5 de dezembro de 2001 e aceito em 10 de setembro de 2002. 